\title{
The Impact of Immediate Verbal Feedback on Swimming Effectiveness
}

Authors' contribution:

A) conception and design of the study

B) acquisition of data

C) analysis and interpretation of data

D) manuscript preparation

E) obtaining funding
Krystyna Zatoń ${ }^{\text {A-E }}$, Stefan Szczepan ${ }^{\text {A-E }}$

University School of Physical Education in Wroclaw, Poland

\section{ABSTRACT}

The main objective of the study was to determine the impact of immediate verbal feedback on swimming effectiveness. Swimming effectiveness was expressed in the subjects reaching their objective, i.e., maximum swimming velocity. The study involved 64 subjects divided into two groups (experimental group $n=32$; control group $n=32$ ). Two measurements - initial (pre-test) and final (post-test) - were conducted. The subjects swam a distance of $25 \mathrm{~m}$ front crawl at maximum velocity. The experimental groups received immediate verbal feedback focused on stroke lengthening, as a shorter stroke length is regarded as the most common reason behind lower swimming velocity. From this perspective, lengthening the stroke is important due to its relation with mechanics and energetics in all styles of swimming. The control group received no verbal feedback. All tests were recorded via video cameras $\left(50\right.$ samples $\left.\cdot \mathrm{s}^{-1}\right)$. The analysis of the kinematic movement parameters (horizontal average swimming velocity over $15 \mathrm{~m}$, time achieved over $15 \mathrm{~m}$ ) was carried out by means of the SIMI Reality Motion Systems 2D software. Analysis of variance with repeated measurements with a Tukey's test demonstrated statistically significant differences $(p<0.05)$ in the tested groups in the case of the kinematic parameters measured in the study. Immediate verbal feedback (IVF) caused an increase of the average horizontal swimming velocity by $2.92 \%(0.04$ $\left.\mathrm{m} \cdot \mathrm{s}^{-1}\right)$. Consequently, the average time needed by the swimmers to cover the distance $(15 \mathrm{~m})$ decreased by $2.94 \%(0.36 \mathrm{~s})$. The results confirmed the effectiveness of the proposed method of teaching and improving the swimming technique using IVF.

KEYWORDS didactic communication, verbal information, immediate feedback, swimming

\section{Introduction}

Learning and teaching, as well as the process of improving motor skills, are associated with constant processing of information both during motor activities and after these activities have been completed (Adams, 1971; Schmidt 1975). Those making movements receive (input) and process information available in their environment in order to make specific motor responses (output). The conditions in which individuals perform a given motor task and the quality of information they receive have a major influence on the ultimate performance of a motor task (Schmidt \& Lee, 2005). It is commonly accepted that learners and those improving their motor skills are helped by augmented feedback complementing intrinsic feedback 
(Magill, 1994). In the past, scientists have analyzed the performance of motor tasks with regard to feedback and have stressed its benefits (Adams, 1987; Magill, 2001; Wulf \& Shea, 2002). The information provided via senses is usually divided into information available before a movement, the so-called feedforward; and available as a result of the movement, the so-called feedback (Schmidt \& Lee, 2005). Taking into account the provenance of feedback, scientists divide it into intrinsic feedback and extrinsic feedback. Intrinsic feedback, also called inherent feedback, is sensory information emerging when a movement is made (Schmidt \& Wrisberg, 2008). Its source may be located outside the body (exteroception) or inside the body (proprioception). Extrinsic feedback, also known as augmented feedback, emerges after a movement is completed and is provided by an external person. It makes it possible to control a motor task by means of a teacher's remarks, the indication of a timer, or a video recording of the task in question (Schmidt \& Wrisberg, 2008). Examples of augmented feedback also include verbal remarks from the coach or teacher. Augmented feedback serves important functions when motor tasks are performed (Schmidt \& Lee, 2005). First, it can provide the learner with information about the performance of the motor task in question. This is an informative function. Second, it can perform a motivating function. It can motivate or activate individuals through the performance of a motor task that seems more interesting. Third, there is also a reinforcing function, which encourages the individual performing the motor task to repeat the task correctly, or a punishing function, preventing actions not conforming to the motor task pattern. Teachers may provide reinforcement both in a verbal and non-verbal form, e.g., through their facial expressions or body language (Annesi, 1998; Silverman, Woods, \& Subramaniam, 1998). The effects of augmented feedback not only depend on its relevance or type, but also on its frequency, precision, volume, and duration (Magill, 1994; Wulf \& Shea, 2002). With regard to the criterion of time, feedback can be provided immediately after a motor task has been completed (immediate feedback) or after some delay (delayed feedback) (Schmidt \& Wrisberg, 2008). In addition, there is concurrent feedback provided while a motor task is being performed (Schmidt \& Lee, 2005).

The present study refers to the processing of information using feedback. It explores the use of verbal transmission of information between the teacher and the learner, as verbal information is the most effective form of transmitting didactic information (Kulik, Kulik, 1988; Munzert, 1994; Landin, 1996; Zatoń, 1989, 2010). In the present study, verbal information was prepared in accordance with the criteria of the information theory and, thanks to the available technology, was given to the learner in real time immediately. Immediate verbal feedback reduces errors in a motor task and eliminates the risk of these errors, serving a preventive function (Marteniuk, 1976; Lee, Swinnen, Serrien, 1994). As a result, the errors are not recorded in long-term memory. This is reflected in an effective performance of motor tasks. A delay in receiving the information causes changes, but these affect long-term memory, in which information is often permanently recorded after it has been processed (Marteniuk, 1976; Lee, Swinnen, Serrien, 1994). Thanks to the solution proposed in the study - using immediate verbal feedback (IVF) - information can be delivered to the learner immediately. Thus far, owing to communication barriers during swimming lessons or classes, this has been difficult. The IVF method presented here can be used in the teaching of the swimming technique and the process of improving the structure of swimming strokes. This suggests an improvement in swimming effectiveness by overcoming communication barriers, providing the learners with immediate information and, consequently, creating a correct motor habit. This is subordinated to a search for the most effective method of improving and teaching complex human motor tasks, including the swimming technique.

Effectiveness is considered to be a factor leading to the achievement of an intended objective (Doran, 1981). In the present study, the objective for the subjects was to maximize the swimming velocity (minimize the time needed to cover the distance in question). The assumption was that the planned objective would be achieved during tests conducted as part of the study. Given the conditions of the experiment (test distance, swimming at maximum velocity, and test sample), the objective was achieved when a change in the swimming velocity was recorded at the final measurement (post-test) in comparison to the initial measurement (pre-test). The effectiveness was measured by the following diagnostic tools: average 
horizontal swimming velocity over a distance of $15 \mathrm{~m}$ and swim time over the distance (kinematic parameters of swimmers' movements).

\section{Objective of the study, the hypothesis, research questions}

The objective of the study was to determine the impact of immediate verbal feedback on swimming effectiveness. The achievement of the objective was based on a verification of the hypothesis. The assumption was that immediate verbal feedback would have an impact on swimming effectiveness. The following research questions were asked to verify the hypothesis:

1. How does the average horizontal swimming velocity over a distance of $15 \mathrm{~m}$ change with the influence of immediate verbal feedback?

2. How does the time needed to cover a distance of $15 \mathrm{~m}$ change with the influence of immediate verbal feedback?

\section{Methods}

The experiment was carried out by means of the parallel group technique involving two comparison groups (control - C; experimental - E) as well as an experimental factor - independent variable - present only in the experimental group. Two measurements - initial (pre-test) and final (post-test) - were made, as was a comparison between the control and the experimental group with regard to the influence of the experimental factor. The studied parameters were analyzed in the Research Laboratory for Movement in Natural Environment, which has a Quality Management Certificate, ISO 9001:2009.

\section{Selection of the study groups}

The study involved 64 individuals. The subjects of the study were non-training males aged between 20 and 23. They were selected for the study on the basis of the following similarity criteria: a) mastery of the standard swimming technique reflected in each swimmer's personal best over $25 \mathrm{~m}$ measured before the main tests; b) somatic parameters, which became an objective premise testifying to the subjects' similar potential with regard to generating propulsion influencing the kinematic parameters of the stroke cycle; c) age.

The assumption made in the study was that the study groups, $(C)$ and (E), could not differ with regard to the subjects' standard swimming technique, described as the time the subjects needed to swim a distance of $25 \mathrm{~m}$, measured before the main tests. A Student's $t$-test carried out as part of the study did not reveal any statistically significant differences between the groups, which confirmed their equality $(\alpha=0.05, p>0.05$, $\mathrm{t}=-0.142 ; \mathrm{df}=62$ ).

In addition, in order to make the groups equal in terms of the subjects' somatic characteristics, the assumption was that the standard deviation could not be greater than $10 \%$ of the average height (Table 1).

Table 1. Characteristic features of people taking part in the study (control group and experimental group)

\begin{tabular}{lllccc}
\hline group & $\mathrm{n}$ & Feature & $\begin{array}{c}\text { Age } \\
(\text { year })\end{array}$ & $\begin{array}{c}\text { Body height } \\
(\mathrm{m})\end{array}$ & $\begin{array}{c}\text { Body weight } \\
(\mathrm{kg})\end{array}$ \\
\hline \multirow{3}{*}{32} & $\bar{x}$ & 20.44 & 1.79 & 74.97 \\
& & $\mathrm{SD} \pm$ & 0.67 & 0.06 & 9.58 \\
& \multirow{2}{*}{32} & $\bar{x}$ & 20.53 & 0.18 & \\
$\mathrm{E}$ & & $\mathrm{SD} \pm$ & 0.92 & 0.06 & 74.31 \\
& & $10 \% \bar{x}$ & \multicolumn{3}{c}{0.18} \\
\hline
\end{tabular}

$10 \% \bar{x}$ - Condition of equality of the study groups in terms of their somatic features.

Source: own study. 
The similarity in the criteria suggested a similar motor potential of the subjects. Thus two uniform groups were formed: a control group $(\mathrm{n}=32)$ and an experimental group $(\mathrm{n}=32)$.

\section{Method of preparing verbal information}

Before the experiment proper began, verbal feedback had been prepared and verified. The aim was to prepare an appropriate verbal message that would extend stroke length, as it is believed that the most frequent cause of a decrease in swimming velocity is a decrease in stroke length (Craig et al., 1985; Hay \& Guimaraes, 1983). Therefore, adjusting and controlling the stroke length, which are related to mechanics and energetics in all styles of swimming, became an object of interest for the authors. Since auditory perception is limited in the reception of information in such situations (Lee, Swinnen, \& Serrien 1994), the structure of verbal feedback was verified. The verification was based on the criteria of efficient didactic communication: 1. The semantic criterion concerning the meaning of terms used in verbal feedback. This means that the meaning of the message could not differ from the scope of the term attributed to the subject. The message transmitted had an identical meaning for the learner and the teacher. 2. The pragmatic criterion, which takes into account the physical capabilities of the individual performing the motor task in question. That is why the level of the study groups was made uniform in terms of their mastery of standard technique. 3. The researchers took into account the structure of human memory. Short-term memory can absorb a limited amount of information, i.e., $7 \pm 2$ (Miller, 1956). Thus, it is important to reject unnecessary information transmitted to those performing the tasks. 4. In this respect, the researchers used a metaphor that directly captures movement. This led to the formulation of a verbal message of "reach farther with your arm," referred to in the study as verbal feedback (independent variable). Given the fact that this information was discrete and was transmitted during swimming, it was categorized as immediate (Schmidt \& Lee, 2005). Since the information was transmitted verbally, it was treated as verbal information. The verbal message in question was positively verified in pilot studies (Zaton \& Szczepan, 2012). Verbal feedback in the third and fourth tests (post-test) was transmitted to the experimental group by one experimenter.

\section{Research procedure}

The study consisted in four tests involving front crawl starting from a stationary, prone position in water. The first and second tests (pre-test) for the control and the experimental group involved swimming $25 \mathrm{~m}$ at maximum velocity without the subjects receiving immediate verbal feedback focused on stroke lengthening. The third and fourth tests (post-test) for the experimental group involved swimming $25 \mathrm{~m}$ at maximum velocity with the subjects being given immediate verbal feedback focused on stroke lengthening (independent variable). In these tests, the control group received no immediate verbal feedback. In order to minimize the effects of fatigue, the subjects performed all tests with the pulse at rest measured in the fifth minute after a 15 -min warm-up.

In order the collect the data related to the kinematic parameters of the swimmers' movements (average horizontal swimming velocity over a distance of $15 \mathrm{~m}$, the swim time over the distance), the subjects were filmed. All tests were recorded at a frequency of 50 frames $\cdot \mathrm{s}^{-1}$, by means of analog video camera (GR-DVL9800, JVC, Japan). The camera was fixed in the middle of the swimming pool above the water. This made it possible to record the analyzed distance of $15 \mathrm{~m}$ covering the so-called clean swimming zone (with the exception of 5-m start and finish zones at both ends of the swimming pool). The real spatial dimensions were determined by means of a coordinate system using two markers contrasting with the environment placed at the $5^{\text {th }}$ and $20^{\text {th }}$ metre of the pool. They were used to identify the so-called clean swimming zone. A marker contrasting with the environment and making it possible to follow the movement of the subjects' bodies was placed in the middle of each swimmer's head (Plagenhoef, 1971). The center of the head in the sagittal plane corresponds to a point located on the temple near the acoustic foramen 
(Zatsiorsky, 1998). Additional illumination (600 lux) was provided for the test site. Each test took place in water at a unified temperature of $27^{\circ} \mathrm{C}$. Figure 1 presents a diagram of the experiment.

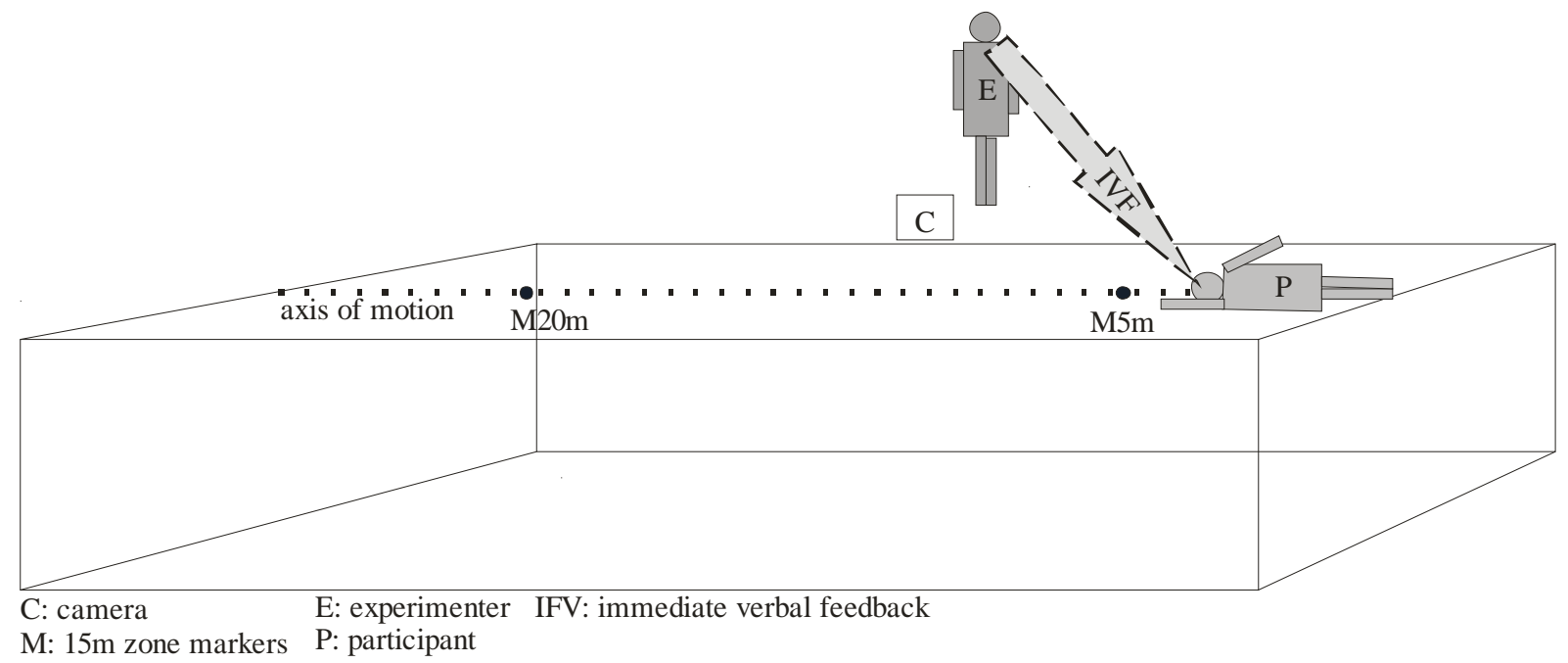

Figure 1. Diagram of the measurement track

Source: own study.

\section{Research device}
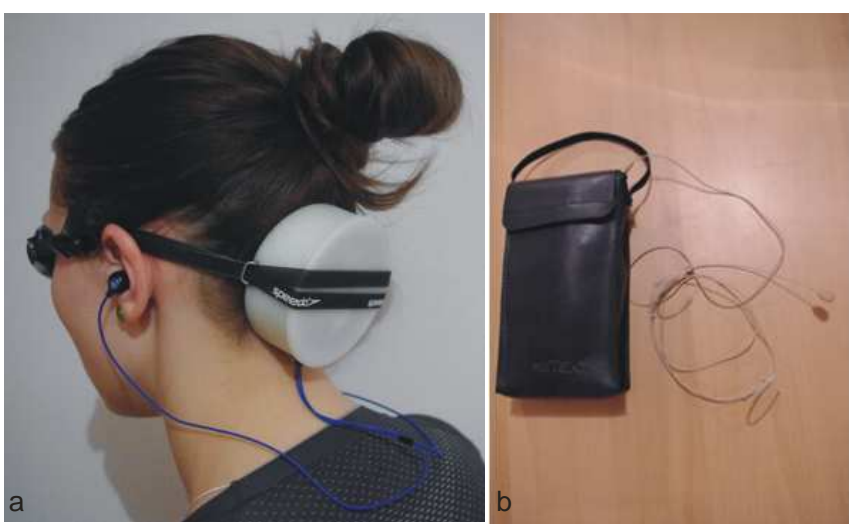

Figure 2. Waterproof communication system making it possible to transmit verbal feedback, a) a subject with the receiver, b) an experimenter's transmitter Source: own study.

\section{The condition of swimming at maximum velocity}

Since stroke length $\left(\mathrm{m} \cdot\right.$ stroke $\left.^{-1}\right)$ is an individual parameter depending on swimming velocity (Craig \& Pendergast, 1979), the subjects performed the tests at maximum velocity; the condition was fulfilled (Table 2). In order to verify the reliability of task performance (swimming at maximum velocity), an assumption was made that the average swim time over the $25 \mathrm{~m}$ in tests 1 and 2 could not be greater than $10 \%$ of the average time for the distance in tests 3 and 4 . That is, the percentage of the average value of swim time over the distance in tests 3 and 4 in relation to the average value of swim time for $25 \mathrm{~m}$ in tests 1 and 2 was defined by the following equation (1):

$$
t_{3,4 / 1,2}=100-\frac{t_{3,4}}{t_{1,2}} \times 100 .
$$

At the same time, the assumption mobilizing the swimmers to achieve maximum velocity (with a tolerance of $10 \%$ ) make the results achieved in the study comparable, at least in the sense of exemplifying the current physical capabilities of the swimmers. 
Table 2. Results of swimming at maximum velocity for the control and experimental groups

\begin{tabular}{|c|c|c|c|c|c|}
\hline No. & 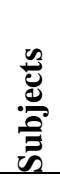 & 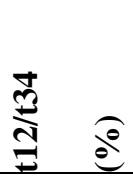 & No. & 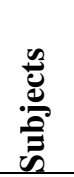 & 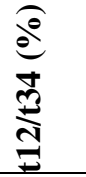 \\
\hline 1 & $\mathrm{C} 1$ & 0.00 & 33 & E1 & 3.34 \\
\hline 2 & $\mathrm{C} 2$ & 0.25 & 34 & E2 & 0.43 \\
\hline 3 & C3 & 6.24 & 35 & E3 & -7.34 \\
\hline 4 & $\mathrm{C} 4$ & -9.82 & 36 & E4 & 3.81 \\
\hline 5 & $\mathrm{C} 1$ & -8.40 & 37 & E5 & -1.61 \\
\hline 6 & $\mathrm{C} 2$ & -4.48 & 38 & E6 & 0.59 \\
\hline 7 & C3 & 2.02 & 39 & E7 & 1.48 \\
\hline 8 & C4 & -1.38 & 40 & E8 & 2.99 \\
\hline 9 & $\mathrm{C} 1$ & 2.19 & 41 & E9 & -3.91 \\
\hline 10 & $\mathrm{C} 2$ & -8.98 & 42 & E10 & 0.44 \\
\hline 11 & C3 & -8.17 & 43 & E11 & 9.13 \\
\hline 12 & C4 & 1.75 & 44 & E12 & 4.41 \\
\hline 13 & $\mathrm{C} 1$ & 9.06 & 45 & E13 & -1.86 \\
\hline 14 & $\mathrm{C} 2$ & -0.74 & 46 & E14 & 4.90 \\
\hline 15 & C3 & -1.83 & 47 & E15 & 0.48 \\
\hline 16 & C4 & -9.43 & 48 & E16 & 6.42 \\
\hline 17 & $\mathrm{C} 1$ & 7.82 & 49 & E17 & 0.70 \\
\hline 18 & $\mathrm{C} 2$ & 1.97 & 50 & E18 & 0.13 \\
\hline 19 & C3 & 1.70 & 51 & E19 & 9.20 \\
\hline 20 & C4 & -0.32 & 52 & E20 & 9.83 \\
\hline 21 & $\mathrm{C} 1$ & 3.30 & 53 & E21 & 0.35 \\
\hline 22 & $\mathrm{C} 2$ & -0.67 & 54 & E22 & -1.16 \\
\hline 23 & C3 & 4.84 & 55 & E23 & -3.12 \\
\hline 24 & C4 & -0.23 & 56 & E24 & 0.15 \\
\hline 25 & $\mathrm{C} 1$ & 1.52 & 57 & E25 & 6.00 \\
\hline 26 & $\mathrm{C} 2$ & 1.45 & 58 & E26 & 4.78 \\
\hline 27 & C3 & -1.51 & 59 & E27 & 1.82 \\
\hline 28. & $\mathrm{C} 4$ & -2.25 & 60 & E28 & 2.92 \\
\hline 29 & $\mathrm{C} 1$ & -0.27 & 61 & E29 & 1.72 \\
\hline 30 & $\mathrm{C} 2$ & -6.21 & 62 & E30 & 0.08 \\
\hline 31 & C3 & -3.54 & 63 & E31 & 0.73 \\
\hline 32 & $\mathrm{C} 4$ & -1.05 & 64 & E32 & 2.54 \\
\hline
\end{tabular}

$\mathrm{t} 12 / \mathrm{t} 34(\%)$ - The condition of swimming at $\mathrm{V}_{\max }$

(a value within the range between -10 and 10 means that the condition of swimming at maximum velocity was met).

Source: own study.

\section{Methods of assessing the kinematic movement parameters}

The analysis of the kinematic movement parameters (horizontal average swimming velocity over $15 \mathrm{~m}$, time over $15 \mathrm{~m}$ ) was carried out by means of the SIMI Reality Motion Systems 2D software (SIMI Reality Motion Systems 2D; GmbH, Germany). During movement recording, all recommendations of the software producer were followed.

\section{Swimming velocity}

Velocity expresses a change in the body position over time. The average horizontal swimming velocity over $15 \mathrm{~m}$ was established on the basis of a direct analysis of movement using the SIMI Reality Motion Systems 2D software.

\section{Time over the distance}

Time measurement for the $15 \mathrm{~m}$ section (the socalled clean swimming zone) was made on the basis of a direct movement analysis by means of the SIMI Reality Motion 2D software with an accuracy of $0.001 \mathrm{~s}$.

\section{Data collection}

The values were achieved on the basis of the following equations (2-5):

The average value of swim time in tests 1 and 2:

$t_{1,2}=\frac{t_{1}+t_{2}}{2}$.

The average value of swim time in tests 3 and 4 :

$$
t_{3,4}=\frac{t_{3}+t_{4}}{2} \text {. }
$$

The percentage of the average value of swim time for the distance in tests 3 and 4 in relation to tests 1 and 2:

$t_{3,4 / 1,2}=100-\frac{t_{3,4}}{t_{1,2}} \times 100$.

The differences in swim times for the distance in tests 1,2 and 3, 4:

$\Delta t=t_{1,2}-t_{3,4}$

\section{Methods of statistical analyses}

Statistical analyses were carried out in the Statistica software (Statistica 9, StatSoft, USA) at a statistical significance level of $\alpha=0.05$. The results are presented as average values, and their differences 
established in the tests. In order to test statistically significant differences between the studied groups ( $\mathrm{C}$ and E) with regard to the parameters measured, the researchers applied a non-parametric Student's $t$-test for independent samples. In order to determine whether the study groups differed between tests $1 \& 2$ (pre-test) and $3 \& 4$ (post-test) with regard to the studied parameters, the researchers used analysis of variance (ANOVA) with repeated arrangements. A post-hoc Tukey test to assess detailed differences between the groups was conducted. The results are presented in the form of Tables and Figures.

\section{Results}

Table 3. Inter-group differences of the studied parameters assessed by means of a Student's $t$-test

\begin{tabular}{llccc}
\hline Parameter & $\begin{array}{l}\text { Test } \\
\mathbf{1 , 2} \text { (pre-test) }\end{array}$ & $\mathbf{t}$ & df & $\begin{array}{c}\text { Significance } \\
\text { (two-sided) }\end{array}$ \\
& $\mathbf{3 , 4}$ (post-test) & & & \\
\hline \multirow{2}{*}{ time to swim $15 \mathrm{~m}(\mathrm{~s})$} & 1,2 & 1.814 & 62 & 0.075 \\
& $\mathbf{3 , 4}$ & $\mathbf{3 . 1 2 9}$ & $\mathbf{6 2}$ & $\mathbf{0 . 0 0 3}$ \\
average horizontal swimming & 1,2 & -1.743 & 62 & 0.086 \\
velocity over $15 \mathrm{~m}\left(\mathrm{~m} \cdot \mathrm{s}^{-1}\right)$ & $\mathbf{3 , 4}$ & $\mathbf{- 2 . 9 6 6}$ & $\mathbf{6 2}$ & $\mathbf{0 . 0 0 4}$ \\
\hline
\end{tabular}

Statistically significant differences at an $\alpha$ level of $0.05(p<0.05)$ are marked in bold.

Source: own study.

The Student's $t$-test showed statistically significant differences between the groups: average horizontal swimming velocity over a distance of $15 \mathrm{~m}$, the swim time over the distance (Table 3 ). This means that the indicated parameters have a diagnostic value in the context of making comparisons between the study groups.

In order to establish detailed differences between the control group and the experimental group with regard to the analyzed parameters in tests $1 \& 2$ and $3 \& 4$, the researchers performed ANOVA with repeated measurements with a Tukey's test (Table 4a,b; Figure 4a,b).
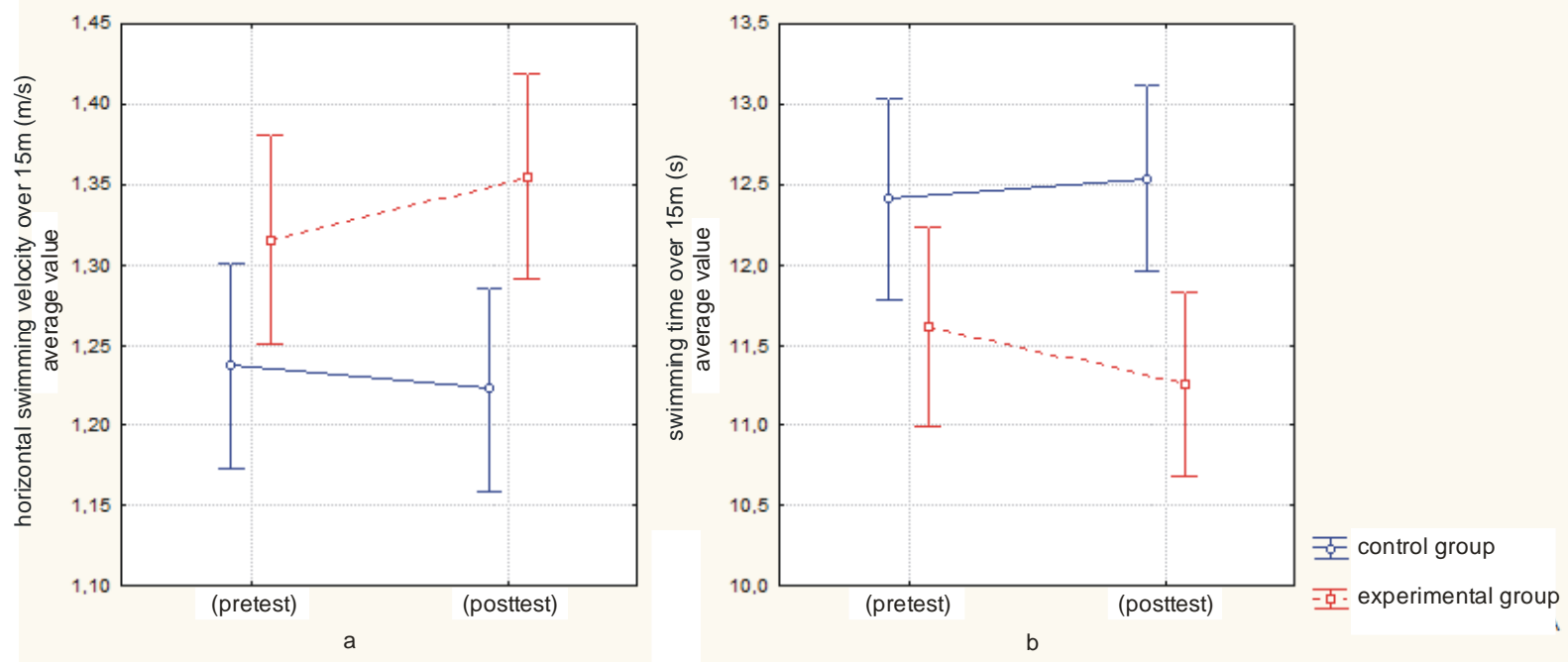

Figure 4. ANOVA with repeated measurements of a) average horizontal swimming velocity over $15 \mathrm{~m}$ and b) swim time over $15 \mathrm{~m}$ in tests $1 \& 2$ (pre-test) and $3 \& 4$ (post-test)

Source: own study.

Figure 4a shows changes in the value of the average horizontal swimming velocity in tests $1 \& 2$ (pretest) and $3 \& 4$ (post-test). Statistically significant differences $(p<0.05)$ occurred between $1 \& 2$ (pre-test) and $3 \& 4$ (post-test) (Table $4 a$ ). In the experimental group in tests $3 \& 4$, the average horizontal swimming velocity over $15 \mathrm{~m}$ increased by $2.92 \%\left(0.04 \mathrm{~m} \cdot \mathrm{s}^{-1}\right)$; in the control group it fell by $1.05 \%$ $\left(0.02 \mathrm{~m} \cdot \mathrm{s}^{-1}\right)($ Table $5 \mathrm{a}, \mathrm{b})$. 
Figure $4 \mathrm{~b}$ shows changes in the value of the average horizontal swimming velocity over $15 \mathrm{~m}$ in tests 1 $\& 2$ (pre-test) and $3 \& 4$ (post-test). Statistically significant differences $(p<0.05)$ occurred between tests $1 \&$ 2 (pre-test) and $3 \& 4$ (post-test) (Table $4 \mathrm{~b}$ ). In the experimental group in tests $3 \& 4$ (post-test) the average swim time over $15 \mathrm{~m}$ decreased by $2.94 \%(0.36 \mathrm{~s})$; in the control group it increased by $1.04 \%(0.13 \mathrm{~s})$ (Table $5 a, b)$.

Table 4a. ANOVA anal with repeated measurements of the average horizontal swimming velocity over $15 \mathrm{~m}$

\begin{tabular}{lccccc}
\hline Intra-object contrast tests & $\begin{array}{c}\text { Type III sum } \\
\text { of squares }\end{array}$ & df & $\begin{array}{c}\text { Mean } \\
\text { square }\end{array}$ & F & $\boldsymbol{p}$ \\
\hline $\begin{array}{l}\text { Dource } \\
\text { measurements }\end{array}$ & 0.004 & 1 & 0.004 & 2.495 & 0.119 \\
$\begin{array}{l}\text { Differences between } \\
\text { measurements by }\end{array}$ & 0.023 & 1 & 0.023 & 12.969 & $\mathbf{0 . 0 0 1}$ \\
$\begin{array}{l}\text { study group } \\
\text { Statistical error }\end{array}$ & 0.109 & 62 & 0.002 & & \\
\hline
\end{tabular}

Statistically significant differences at an $\alpha$ level of $0.05(p<0.05)$ are marked in bold.

Source: own study.

Table 4b. ANOVA with repeated measurements of the average swim time over $15 \mathrm{~m}$

\begin{tabular}{lccccc}
\hline $\begin{array}{l}\text { Intra-object contrast tests } \\
\text { Type III sum } \\
\text { Source }\end{array}$ & $\begin{array}{c}\text { of squares } \\
\text { df }\end{array}$ & $\begin{array}{c}\text { Mean } \\
\text { square }\end{array}$ & F & $\boldsymbol{p}$ \\
\hline $\begin{array}{l}\text { Differences between } \\
\text { measurements }\end{array}$ & 0.432 & 1 & 0.432 & 2.192 & 0.144 \\
$\begin{array}{l}\text { Differences between } \\
\text { measurements by }\end{array}$ & 1.882 & 1 & 1.882 & 9.537 & $\mathbf{0 . 0 0 3}$ \\
$\begin{array}{l}\text { study group } \\
\text { Statistical error }\end{array}$ & 12.233 & 62 & 0.197 & & \\
\hline
\end{tabular}

Statistically significant differences at an $\alpha$ level of $0.05(p<0.05)$ are marked in bold.

Source: own study.

Table 5a. Changes in parameter values in tests $3 \& 4$ (post-test) in comparison with tests $1 \& 2$ in percentages

\begin{tabular}{|c|c|c|c|c|c|c|}
\hline Parameter & Group & $\mathbf{N}$ & $\bar{x}$ & SD \pm & Min & Max \\
\hline \multirow{3}{*}{$\begin{array}{l}\text { swim time over } 15 \mathrm{~m} \\
(\%)\end{array}$} & $\mathrm{C}$ & 32 & $1.04 \%$ & $5.64 \%$ & $-9.98 \%$ & $12.50 \%$ \\
\hline & $\mathrm{E}$ & 32 & $-2.94 \%$ & $3.48 \%$ & $-12.52 \%$ & $2.57 \%$ \\
\hline & Total & 64 & $-0.95 \%$ & $5.07 \%$ & $-12.52 \%$ & $12.50 \%$ \\
\hline average horizontal & $\mathrm{C}$ & 32 & $-1.05 \%$ & $5.66 \%$ & $-12.36 \%$ & $10.02 \%$ \\
\hline swimming velocity over & $\mathrm{E}$ & 32 & $2.92 \%$ & $3.42 \%$ & $-2.54 \%$ & $11.78 \%$ \\
\hline $15 \mathrm{~m}(\%)$ & Total & 64 & $0.93 \%$ & $5.06 \%$ & $-12.36 \%$ & $11.78 \%$ \\
\hline
\end{tabular}

A negative result denotes a decrease in the value by an average of - $n$. A positive result denotes an increase in the value by an average of $-n$.

Source: own study.

Table 5b. Changes in parameter values in tests $3 \& 4$ (post-test) in comparison with tests $1 \& 2$ (pre-test) in units for parameters

\begin{tabular}{lllllll}
\hline Parameter & Group & $\mathbf{N}$ & $\bar{x}$ & SD \pm & Min & Max \\
\hline \multirow{2}{*}{ swim time over 15 m (s) } & C & 32 & 0.13 & 0.76 & -1.44 & 1.77 \\
& Total & 32 & -0.36 & 0.46 & -1.72 & 0.30 \\
average horizontal & C & 32 & -0.12 & 0.67 & -1.72 & 1.77 \\
swimming velocity over & E & 32 & 0.04 & 0.07 & -0.16 & 0.13 \\
$15 \mathrm{~m}\left(\mathrm{~m}^{-1} \mathrm{~s}^{-1}\right)$ & Total & 64 & 0.01 & 0.06 & -0.16 & 0.14 \\
\hline
\end{tabular}


A negative result denotes a decrease in the value by an average of - $\mathrm{n}$. A positive result denotes an increase in the value by an average of $-\mathrm{n}$.

Source: own study.

\section{Discussion}

The objective of the study was to determine the impact of immediate verbal feedback on swimming effectiveness. The authors also wanted to find a method for supporting those performing motor tasks in order to increase the effectiveness of their motor performance. The assumption was that verbal feedback would increase swimming effectiveness (as the intended objective). The results achieved in the study confirmed the hypothesis. The most important discovery of the study is the confirmation of the fact that verbal feedback given immediately contributes to a correct performance of a motor task.

Stroke length control is an example here. Verbal instruction directed at stroke length elongation with intention to prevent technique flaws in the temporal-spatial structure of swimming movements. If stroke length shortens while movement frequency remains unchanged or decreases, the temporal-spatial structure of swimming is considered erroneous. It results in lower swimming velocity (Ungerechts \& Theismann, 1995; Hay, 2002). That is why in the presented study immediate verbal feedback was used to prevent this error from occurring. In the experimental group in tests 3 and 4 (posttest), the average swimming velocity increased by $2.92 \%\left(0.04 \mathrm{~m} \cdot \mathrm{s}^{-1}\right)$, which means that the intended objective was achieved. The results should be a step in determining the significance in swimming of verbal feedback given immediately.

For many years, error elimination and correction processes have been the teachers' role. it is especially possible due to immediate verbal feedback, which makes removing short-term memory errors possible. However, immediate verbal feedback needs to be properly prepared in order to use it purposely. For proper preparation, effective didactic communication (semantics, syntactics, and pragmatics) principles are recommended. Other effective communication criteria are: number, frequency, and accuracy of information transfer (Williams \& Hodges, 2005). Additional criterion crucial to effectiveness of teaching and developing motor actions is the content of information (Magill, 1994; Wulf \& Shea, 2002). In the presented study, the content of the transferred information was purposely limited due to the experimental conditions and the immediate character of communication, which is why unnecessary data was reduced to minimum. Verbal information prepared in this way was clearly understood, consisted of a minimal amount of words, and it was possible to deliver it immediately.

Our work examined two aspects impeding the process of teaching of swimming and technique improvement.

Firstly, the interference in didactic communication - it is particularly noticeable when an exercise is executed in an atypical environment, for example in water. The aquatic environment hinders the reception of information because a number of disruptive factors, such as the distance between the teacher and the learner or ambient noise, favor errors in a given exercise. Thus, the environmental factors make it hard to use verbal feedback to its full communicative potential in the process of swimming acquisition or technique improvement (Landin, 1996; More \& Franks, 1996; Zatoń, 2010). It may also be challenging to immediately eliminate or prevent (within short-term memory) errors as or before they appear.

Secondly, providing the learners with delayed feedback - the fact that immediate feedback is part of the error detection and correction mechanism has been established by numerous research works (Lee et al., 1994; Schmidt \& Lee, 1999). It has been widely used as a one of the methods to reduce the number of errors or prevent them from occurring. The authors of such works found that immediate verbal feedback indeed helps reduce the number of errors and plays a preventive role. Consequently, erroneous patterns are not stored in long-term memory and assimilated. That is how correct motor habits become the final result of the process of swimming acquisition or technique improvement.

The selection of information (verbal, pictorial) is particularly important when the motor task is performed in a different environment. The water environment hinders didactic perception due to interfering 
factors: the distance between the teacher and the learner and noise is conducive to errors in motor tasks. That is why in the presented study, information transfer was used with the aid of a communication device that eliminated communication barriers in the aquatic environment. It created conditions to understand didactic information and to prevent errors in movement structure. When the errors are eliminated immediately after they occur by means of immediate information, they cannot be consolidated, which is related to the process of inhibition in the central nervous system, and motor memory (Schmidt \& Lee, 1999). This type of activity is also regarded as the prevention of errors in the teaching of swimming, a fact that the authors of the present study wanted to stress as well.

Swimming is considered to be a motor task in which augmented feedback is treated as an important type of information (Zaton \& Klarowicz, 2003). Tests carried out in the water environment involving information given to the learner immediately suggest that such information is effective. This happened, in particular, when the swimming pace was set by a timer placed on the bottom of the swimming pool (Perez, Llana, Brizuela, \& Encarnacion, 2009) or the value of strength achieved on a swimming ergometer (Petriaev \& Kleshnev, 2006). Many of these studies became possible thanks to advances in technology, which have produced tools useful in the work of swimming teachers and coaches.

Given the number of unexplored issues connected with didactic communication, studies in this field should be continued. The authors are planning another project in which they will attempt to establish whether the results of the present experiment can be used in the teaching of other motor structures of the swimming technique, e.g., early vertical forearm technique, holding the elbow high in the recovery phase in the front crawl, elements of motor coordination, and others. What may prove helpful in the verification of other hypotheses concerning improvement in the performance of individuals learning to swim and developing their swimming technique is the communication tool constructed for the purpose of the study and the proposed IVF method using immediate verbal feedback.

\section{Conclusions}

In all swimming styles, stroke length is considered an essential kinematic parameter of the swimming cycle. It is important for swimming mechanics and energetics. If stroke length shortens while movement frequency remains unchanged or decreases, the temporal-spatial structure of swimming is considered erroneous. It results in lower swimming velocity. Immediate feedback (transmitted while the exercise is being executed) prevents errors in the spatial-temporal structure of swimming. A verbal message conveyed to the swimmer in the process of swimming helps increase the stroke length value which, at a constant stroke rate, results in higher horizontal swimming velocity and, as a result, minimizes the time needed to cover the distance, which achieves the intended objective of the study. The presented method involving immediate verbal feedback makes it possible to use verbalization as the most effective information carrier in the water environment. It thus becomes possible to use verbal feedback to control swimmers' movements in real time with no delay. The authors have also confirmed the usefulness of their device for wireless communication between the coach and the swimmer during swimming, i.e., when perception is disrupted. To speak more generally, it is possible to use the presented IVF method with the indicated communication device to add some variety to the technique of transmitting information. The application of the proposed method of providing immediate verbal feedback by means of a special communication device enriches the transmission of instruction content. The results of the authors' study can be used in physical education (in the teaching and improving of the swimming technique to prevent errors, eliminate them immediately, and improve swimming economy), in leisure activities (to develop motor potential), and in competitive swimming (to improve results). The results of the present experiment can be used in the teaching of other motor structures of the swimming technique, which indicates possible practical applications of the IVF method. A direct result of the implementation of the results in the teaching and coaching practice is improved effectiveness of instruction methods. 


\section{REFERENCES}

Adams, J. (1971). A closed-loop theory for motor learning. Journal of Motor Behavior, 3, 111-150.

Annesi, J.J. (1998). Effects of computer feedback on adherence to exercise. Perceptual and Motor Skills, 87, 723-730.

Craig, A., Skehan, P., Pawelczyk, J., et al. (1985). Velocity, stroke rate and distance per stroke during elite swimming competition. Med Sci Sports Exerc, 17:625-34.

Craig, A.B. Jr, Pendergast, D.R. (1979). Relationships of stroke rate, distance per stroke and velocity in competitive swimming. Medicine and Science in Sports and Exercise, 11, 278-283.

Doran, G.T. (1981). There's a S.M.A.R.T. way to write management's goals and objectives. Management Review, 70(11), 35-36.

Fiłon, M. (1985). Doskonalenie stylu grzbietowego za pomocą informacyjnego systemu stabilizującego parametry czasowo-przestrzenne techniki pływania /Perfecting the backstroke using the information system which stabilizes spatio-temporal parameters of swimming technique. Zeszyty Naukowe AWF we Wroctawiu, 38, 147-156.

Hay, J.G. (2002). Cycle rate, length and speed of progression in human locomotion. J. Appl. Biomech, 18, $257-270$.

Hay, J.G., Guimaraes, A.C.S., Grimston, S.K.A. (1983). Quantitive Look at Swimming Biomechanics. In J.G. Hay (Ed.), Starting, Stroking \& Turning. A Compilation of Research on the Biomechanics of Swimming (pp. 1-4). Iowa, The University of Iowa.

Kulik, J.A., Kulik, C.C. (1988). Timing of feedback and verbal learning. Review of Educational Research, 58(1), 79-97. Landin, D. (1996). The role of verbal cues in skill learning. Quest, 46, 299-313.

Lee, T., Swinnen, S., Serrien, J. (1994). Cognitive effort and motor learning. Quest, 46, 328-344.

Magill, R. (1994). The influence of augmented feedback during skill learning depends on characteristics of the skill and the learner. Quest 46, 314-327.

Magill, R. A. (2001). Augmented feedback in motor skill acquisition. In R.N. Singer, H.A Hausenblas, C.M. Janelle (Eds.), Handbook of sport psychology (pp. 86-114). New York, Wiley.

Marteniuk, R.G. (1976). Information Processing in Motor Skills. Holt, New York. Rinehart and Winston.

Miller, G.A. (1956). The magical number seven, plus or minus two: Some limits on our capacity for processing information. Psychological Review, 63, 81-97.

More, K.G., Franks, I.M. (1996). Analysis and modification of verbal coaching behaviour: The usefulness of a datadriven intervention strategy. J. Sports Sci, 14, 523-543.

Munzert, J. (1994). Verbo-motorische lernformen im sport./Verbal-motor learning in sport. Brennpunkte der Sportwissenschaft. 8(2), 248-258.

Pérez, P., Llana, S., Brizuela, G., Encarnación, A. (2009). Effects of three feedback conditions on aerobic swim speeds. J Sport Sci Med, 8, 30-36.

Petriaev, A., Kleshnev, I.. (2006). Diagnostic. Training and realisation of strength condition of swimmers with use of feedback diagnostic simulator “ART”. Portuguese Journal of Sport Sciences, 6 (Suppl 2), 244-246.

Plagenhoef, S. (1971). Patterns of Human Motion - a Cinematographic Analysis. Englewood Cliffs, Prentice-Hall Inc.

Schmidt, R.A. (1975). Schema theory of discrete motor skill learning. Psychological Review, 82.

Schmidt, R.A., Lee, T.D. (2005). Motor Control and Learning. A Behavioral Emphasis. (4 ${ }^{\text {th }}$ ed.). Champaign IL, Human Kinetics.

Schmidt, R.A., Wrisberg, C.A. (2008). Motor Learning and Performance (4 ${ }^{\text {th }}$ ed.). Champaign, IL, Human Kinetics.

Silverman, S.S., Woods, A.M., Subramaniam, P.R. (1998). Task structures, feedback to individual students, and student skill level in physical education. Research Quarterly for Exercise and Sport, 69, 420-424.

Ungerechts, B.E., Theismann, M. (1995). Changes of stroke rate during swimming races. In K. Hakkinen, L. Keskinen, V. Komi, A. Mero (Eds.), XV th Congress of the International Society of Biomechanics (pp. 946-947). Jyvaskyla, Finland: Gummerus Printing.

Williams, A. M., Hodges J. N. (2005). Practice, instruction and skill acquisition in soccer: Challenging tradition. $J$. Sports Sci, 23(6), 637-650.

Wulf, G., Shea, C. (2002). Principles derived from the study of simple skills do not generalize to complex skill learning. Psychonomic Bulletin \& Review, 9, 185-211.

Zatoń, K. (1989). Struktura przekazów słownych nauczycieli wychowania fizycznego/Structure of verbal information of physical education teachers. Zeszyty Naukowe AWF we Wrocławiu, 50, 55-66.

Zatoń, K. (2010). The role of verbal information about sensory experience from movement apparatus in the process of swimming economization. In P.L. Kjendlie, R.K. Stallman, J. Cabri (Eds.), Biomechanics and Medicine in Swimming 
XI: proceedings of the XI International Symposium for Biomechanics and Medicine in Swimming (pp. 349-351). Oslo: Norwegian School of Sport Sciences.

Zatoń, K., Klarowicz, A. (2003). Mowa jako czynnik uświadamiający wrażliwość kinestetyczną w procesie nauczaniauczenia się czynności ruchowych w pływaniu/Speech as a factor causing the awareness of kinesthetic sensibility in the process of teaching-learning of motor function in swimming. Człowiek $i$ Ruch, 2(8), 45-53.

Zatoń, K., Szczepan, S. (2012). The Effect of Immediate Verbal Feedback on the Efficiency and the Effectiveness of Swimming. Baltic Journal of Health and Physical Activity, 4(2), 91-103.

Zatsiorsky, V.M. (1998). Kinematics of human motion. Champaign IL: Human Kinetics.

AUTHOR'S ADDRESS:

Stefan Szczepan

University School of Physical Education in Wroclaw, Poland

Department of Swimming

35 Paderewski Avenue

51-612 Wrocław, Poland

Email: Stefan.Szczepan@awf.wroc.pl 